(2) Open Access Full Text Article

\title{
Investigation of ischemic and demyelinating lesions by cerebral vasoreactivity based on transcranial Doppler sonography: a comparative study
}

This article was published in the following Dove Press journal: Neuropsychiatric Disease and Treatment

\author{
Anahita Zoghi' \\ Peyman Petramfar ${ }^{2}$ \\ Alireza Nikseresht ${ }^{2}$ \\ Ehsan Sakhaee' \\ 'Department of Neurology, Shahid \\ Beheshti University of Medical \\ Sciences, Tehran, Iran; ${ }^{2}$ Clinical \\ Neurology Research Center, \\ Department of Neurology, Shiraz \\ University of Medical Sciences, \\ Shiraz, Iran
}

Correspondence: Peyman Petramfar Department of Neurology, Namazi Hospital, Shiraz University of Medical Sciences, Zand Avenue, Shiraz, Iran Tel/fax +98 7l 36474332

Email petramfar@yahoo.com
Purpose: Variations of cerebral blood flow in response to hypoxia and hyperoxia in different disease conditions can provide new insights into disease etiopathogenesis. This study aimed to determine the characteristics of cerebral vasoreactivity for ischemia and demyelination.

Materials and methods: This case-control study included: 28 patients with lacunar infarctions verified by history, physical examination, and MRI; 28 age- and sex-matched healthy controls; 28 patients with relapsing-remitting multiple sclerosis (MS), based on McDonald criteria; and 28 age- and sex-matched healthy controls for the MS group. Transcranial Doppler sonography was undertaken in all subjects to calculate the mean flow velocity (MFV) of the right middle cerebral artery (MCA) and, after a breath-holding (BH) maneuver, the breath-holding index (BHI) was determined.

Results: There was no significant difference of BHI and changes of MFV of the MCA in MS patients compared to controls ( $1.02 \pm 0.4$ vs $1.02 \pm 0.3, p=0.993$; and $16.8 \pm 8.1$ vs $11.3 \pm 10.8$, $p=0.057)$. BHI in patients with lacunar infarctions was significantly lower ( $0.8 \pm 0.4$ vs $1.2 \pm 0.3$, $p<0.001)$ compared to controls. The BHI $(p=0.040)$ and variations of MFV of MCA ( $p=$ $0.007)$ in MS patients were significantly higher than in patients with lacunar infarctions. The vasoreactivity of demyelinating lesions was higher than that of ischemic ones.

Conclusion: Therefore, cerebral vasoreactivity determined by transcranial Doppler could be utilized for differentiating demyelinating from ischemic lesions.

Keywords: cerebral vasoreactivity, multiple sclerosis, ischemia, demyelination

\section{Introduction}

Stroke is among the leading causes of morbidity, mortality, and disability among both developed and developing countries, accounting for approximately 15 million new cases and five million deaths annually. ${ }^{1,2}$ Approximately $85 \%$ of all strokes are ischemic and $10 \%-15 \%$ are reported to be hemorrhagic. ${ }^{3}$ Lacunar infarction is the result of ischemia in small penetrating arteries called lacunes, and it has unique clinical and pathological features. It has been demonstrated that cerebral autoregulation is impaired after ischemia and stroke due to the ischemic damage to cerebral arterioles and capillaries. ${ }^{4}$ Other chronic conditions affecting blood vessels such as hypertension can also result in impaired cerebral autoregulation. ${ }^{5}$ In other words, ischemia results in endothelial cell and receptor dysfunction as well as smooth muscle activation, leading to impaired cerebral autoregulation. ${ }^{6}$

Multiple sclerosis (MS) is a chronic, inflammatory, demyelinating, and degenerative disease of the central nervous system with an estimated prevalence of 2.93 per 100,000 inhabitants that has a subtle and undetermined pathological mechanism. An acute MS lesion is characterized by hyperintense lesions in T2-weighted and 
diffusion-weighted (DW) brain MRI and hypointense lesions on apparent diffusion coefficient (ADC) imaging that are similar to findings in acute lacunar ischemia. Thus, it is important to differentiate these lesions from ischemic changes. $^{7}$ Proposed mechanisms of MS include inflammatory changes, demyelination, axonal degeneration, and oligodendrocyte loss. ${ }^{8}$ However, recent studies have revealed a close relationship between cerebral vasculature, blood flow, and MS. ${ }^{9,10}$ Histopathological studies of MS patients have revealed several microvascular changes in cerebral tissue including thickening or hyalinization of vein walls and small veins and capillary thrombosis suggesting an ischemic basis for the disease. ${ }^{11}$ As mentioned above, lacunar infarction and MS plaques share similar characteristics in T2-weighted and DW brain MRI and ADC imaging. This intensifies the differentiation between these two conditions and further management, because management of these two condition is entirely different. However, it is suggested that cerebrovascular reactivity is normal in different disease activity levels of MS. ${ }^{10}$ Thus, evaluating cerebral vasoreactivity may be an appropriate tool for differentiating ischemic lesions from demyelinating ones.

Cerebral vasoreactivity could be evaluated through different methods including the transcranial Doppler (TCD) sonography, ${ }^{12}$ dynamic susceptibility contrast perfusion MR imaging, ${ }^{13}$ hypercapnia MRI study, ${ }^{9}$ and measurement of circulating endothelin-1 and asymmetric dimethylarginine. ${ }^{14}$ Flow velocities in the large cerebral arteries and velocity changes after vasodilatory stimulus, such as acetazolamide, $\mathrm{CO}_{2}$, or apnea, could be evaluated by means of TCD sonography. ${ }^{15}$ Increased $\mathrm{CO}_{2}$ levels induced by breath holding results in an autoregulatory vasodilatation, and an increase in cerebral blood flow (CBF) to the cortex. ${ }^{16,17}$ This increase in CBF can provide precious and valuable information about vascular integrity and proper function. ${ }^{12}$ As data on the differentiating properties of cerebral vasoreactivity evaluation by means of TCD sonography are scarce, we undertook this study to investigate changes in cerebrovascular vasomotor reactivity induced by breath holding using TCD sonography in patients with MS and lacunar infarction.

\section{Materials and methods}

\section{Patients}

This case-control study was conducted, during a 12-month period from March 2011 to March 2012 in the Department of Neurology, Nemazee Hospital, and the Motahari Clinic, both tertiary health care centers affiliated with the Shiraz University of Medical Sciences. In this study, we included four groups of participants. The first study group included 28 patients admitted to the Department of Neurology of Nemazee Hospital with a diagnosis of lacunar infarction. Lacunar infarction was diagnosed according to hyperintense lesions on T2-weighted brain MRI. In addition, all patients had DWI sequences, and we included both acute and old lacunar infarctions. All subjects suffered from motor and/or sensory deficit and ataxic signs without signs of cortical involvement. All of the ischemic lesions in these patients were found in the deep brain within the territory of a single perforating artery with a maximum diameter of $15 \mathrm{~mm}$ on imaging. A group of 28 healthy volunteers matched by sex and age were included as the control group of subjects with lacunar infarction. Furthermore, we included 28 patients with clinically diagnosed relapsing-remitting (RR) MS according to the McDonald criteria who were referred due to an acute relapse. ${ }^{15}$ Hemispheric involvement was confirmed in all of the patients by detecting hyperintense lesions on T2-weighted brain MRI. We also included 28 age- and sex-matched healthy volunteers as controls for the MS group. Healthy volunteers were selected from those referred to the neurology departments of our centers as patients' relatives or at the Motahari clinic for routine follow-ups.

Exclusion criteria for two control groups and patients with MS included any history of transient ischemic attack (TIA) or cerebrovascular accident (CVA), severe carotid artery stenosis $(>70 \%)$, cardiac problem (atrial fibrillation, recent myocardial infarction [MI], endocarditis, dilated cardiomyopathy), COPD, hypertension (systolic blood pressure $>140 \mathrm{mmHg}$, diastolic blood pressure $>90 \mathrm{mmHg}$ ), diabetes mellitus (DM; fasting blood sugar [FBS] $>126 \mathrm{mg} / \mathrm{dL}$ ), hypercholesterolemia (total cholesterol $>200 \mathrm{mg} / \mathrm{dL}$ ), obesity, smoking $(>1$ pack-year), congestive heart failure (greater than New York Heart Association Grade I), hematologic disease, and cancer. Moreover, we excluded those participants who were being treated with hormonal substances, nitrates, $\beta$-blocking agents, calcium channel blockers, anticoagulants, and vasodilatory drugs. Exclusion criteria for those diagnosed with lacunar infarction were severe carotid artery stenosis $(>70 \%)$, cardiac problem (atrial fibrillation, recent MI, endocarditis, dilated cardiomyopathy), COPD, being treated with hormonal substances, nitrates, $\beta$-blocking agents, calcium channel blockers, anticoagulants, and vasodilatory drugs for up to 1 week prior to the study. Case and control groups were matched for sex and age, because these two variables have been proved to affect cerebrovascular vasomotor reactivity as well as the breath-holding index (BHI). ${ }^{18}$ Patients with 
MS who had acute lacunar infarctions diagnosed with DWI were excluded.

The study protocol was approved by the institutional review board of Shiraz University of Medical Sciences, and the approval of the Ethics Committee was obtained before beginning the study. All participants provided written informed consent before inclusion in the study.

\section{Study protocol}

All subjects underwent a careful cardiologic and neurological examination by the neurologist resident and a cardiologist. Electrocardiography (ECG) was conducted in order to rule out the cardiovascular diseases. Laboratory evaluation included FBS, total cholesterol and complete blood count in order to detect those with DM, hypercholesterolemia, and anemia. All subjects underwent Doppler sonography of bilateral carotid arteries in order to rule out severe carotid artery stenosis at the same time as the TCD sonography study.

TCD sonography was carried out in all patients using a TCD DWL Multidop machine (scimed Ltd/TC22) with a 2-MHz, hand-held, pulsed-wave Doppler probe. All the TCDs were undertaken by an experienced neurology resident under the supervision of the neurology attending. TCD sonography was done via a temporal window in a quiet room after at least 5 minutes of rest in the supine position. The probe was adjusted until a maximal ultrasonic signal was obtained. This point was approximately at a depth of $50 \mathrm{~mm}$. The probe was held in position in order to evaluate the TCD sonography parameters.

Mean flow velocity (MFV) in the middle cerebral artery (MCA), was recorded for 1 minute. Thereafter, cerebrovascular vasoreactivity to hypercapnia was evaluated by the means of a breath-holding maneuver according to the procedure previously described by Markus and Harrison. ${ }^{12}$ After normal breathing, the subjects were instructed to hold their breath for 30 seconds. During the breath-holding period, the MFV in the MCA was recorded continuously. Subjects were requested not to perform a Valsalva maneuver during breath holding because it would result in blood pressure (BP) changes and disturb cerebral hemodynamics.

Then, the BHI was calculated by the following formula:

$$
\operatorname{BHI}(\%)=\frac{\operatorname{MFV}(\text { apnea })-\operatorname{MFV}(\text { rest })}{\operatorname{MFV}(\text { rest }) \times 30} \times 100
$$

\section{Statistical analysis}

Based on $95 \%$ CI and $80 \%$ power and to detect significant differences regarding BHI between the four study groups
( $p=0.05$, two-sided), 28 patients were required in each group. To compensate for possible unevaluable data, we enrolled 112 patients in each study group. The Statistical Package for Social Sciences (SPSS) for Windows, version 18.0 (SPSS, Chicago, IL, USA) was used for data analysis. Between-group differences were compared using one-way analysis of variance (ANOVA). For comparison between groups, Bonferroni post hoc test was used. The MannWhitney $U$-test was used for comparison between groups in non-normal distribution. Categorical variables were analyzed using the chi-square test. In order to compensate for confounders, we also ran a multivariate logistic regression model encompassing age and sex as independent factors. Data are reported as mean $\pm \mathrm{SD}$ and proportions as appropriate. A two-sided $p$-value of less than 0.05 was considered statistically significant.

\section{Results}

A total of 112 subjects in four study groups of lacunar infarction and control as well as MS and control were included in this study. There were 48 (42.9\%) men and 64 (57.1\%) women among the participants. The mean age of all the participants was found to be $41.1 \pm 13.7$ (ranging from 19 to 70) years. The baseline characteristics of the patients and the controls are summarized in Table 1.

The mean BHI in those with lacunar infarction was found to be significantly lower when compared to their age- and sex-matched controls $(0.8 \pm 0.4$ vs $1.2 \pm 0.3 ; p<0.001)$. There was no significant difference between those with lacunar infarction and their controls with regard to $\mathrm{MFV}_{\text {rest }}$ $(p=0.264), \mathrm{MFV}_{\text {apnea }}(p=0.227)$, and MFV variations $(p=0.649)$ (Table 2). The mean BHI in those with MS was found to be comparable with their age- and sex-matched controls $(1.02 \pm 0.4$ vs $1.02 \pm 0.3 ; p=0.993)$. There was no significant difference between those with MS and their

Table I Baseline characteristics of 112 patients and controls included in the current study

\begin{tabular}{|c|c|c|c|c|}
\hline & $\begin{array}{l}\text { MS } \\
(n=28)\end{array}$ & $\begin{array}{l}\text { Control } \\
(n=28)\end{array}$ & $\begin{array}{l}\text { Lacunar } \\
\text { infarction } \\
(\mathbf{n}=\mathbf{2 8})\end{array}$ & $\begin{array}{l}\text { Control } \\
(n=28)\end{array}$ \\
\hline Age (years) & $29.85 \pm 6.8$ & $30.57 \pm 6.6$ & $52.1 \pm 10.2$ & $51.8 \pm 9.7$ \\
\hline \multicolumn{5}{|l|}{ Gender } \\
\hline Men (\%) & 7 (25.0\%) & 7 (25.0\%) & 17 (60.7\%) & 17 (35.4\%) \\
\hline Women (\%) & $2 \mathrm{I}(75.0 \%)$ & 21 (75.0\%) & II (39.3\%) & II (39.3\%) \\
\hline $\begin{array}{l}\text { Disease duration } \\
\text { (months) }\end{array}$ & $36.3 \pm 12.6$ & $N / A$ & N/A & $N / A$ \\
\hline EDSS & $2.83 \pm 1.56$ & $\mathrm{~N} / \mathrm{A}$ & $\mathrm{N} / \mathrm{A}$ & $N / A$ \\
\hline
\end{tabular}

Abbreviations: EDSS, Extended Disability Status Scale; ms, multiple sclerosis. 
Table 2 TCD sonography characteristics of subjects with lacunar infarction and healthy individuals

\begin{tabular}{llll}
\hline & $\begin{array}{l}\text { Lacunar infarction } \\
(\mathbf{n}=\mathbf{2 8})\end{array}$ & $\begin{array}{l}\text { Controls } \\
(\mathbf{n}=\mathbf{2 8})\end{array}$ & p-value \\
\hline $\mathrm{BHI}(\%)$ & $0.8 \pm 0.4$ & $1.2 \pm 0.3$ & $<0.001$ \\
$\mathrm{MFV}_{\text {rest }}$ & $47.2 \pm 14.2$ & $51.4 \pm 13.4$ & 0.264 \\
$\mathrm{MFV}_{\text {apnea }}$ & $58.5 \pm 17.7$ & $63.9 \pm 14.8$ & 0.277 \\
$\mathrm{MFV}$ variations & $11.2 \pm 6.4$ & $12.4 \pm 11.9$ & 0.649 \\
\hline
\end{tabular}

Abbreviations: $\mathrm{BHI}$, breath-holding index; MFV, mean flow velocity; TCD, transcranial Doppler.

controls with regard to $\mathrm{MFV}_{\text {rest }}(p=0.849), \mathrm{MFV}_{\text {apnea }}$ $(p=0.448)$, and MFV variations ( $p=0.057)$ (Table 3$)$.

The mean BHI in those with MS was found to be significantly higher when compared to those with lacunar infarction $(1.02 \pm 0.4$ vs $0.8 \pm 0.4 ; p=0.040)$. In the same way, patients with MS had significantly higher $\operatorname{MFV}_{\text {rest }}(p=0.010)$, $\operatorname{MFV}_{\text {apnea }}(p=0.002)$, and MFV variations $(p=0.007)$ when compared to those with lacunar infarctions (Table 4). In order to compensate for confounders such as age and sex, we ran a multivariate logistic regression model. We found that, after compensating for confounders, patients with MS had comparable BHI to those with lacunar infarctions. In addition, the BHI was comparable between the MS patients and the healthy controls of the lacunar infarction group $(1.02 \pm 0.4$ vs $1.2 \pm 0.3 ; p=0.863)$.

\section{Discussion}

In this case-control study, we tried to investigate the differentiating properties of BHI measured by TCD sonography in ischemic and demyelinating brain lesions. We found that BHI was significantly lower in those with lacunar infarcts when compared to their age- and sex-matched healthy controls demonstrating impaired cerebral vasoreactivity in ischemia even in small quantity (lacunar infarction). However, patients with MS were found to have intact cerebral vasoreactivity based on the observation that the BHI was identical between MS patients and healthy controls. Correspondingly, the BHI was significantly higher in MS patients when compared to

Table 3 TCD sonography characteristics of subjects with MS and healthy individuals

\begin{tabular}{llll}
\hline & $\begin{array}{l}\text { MS } \\
(\mathbf{n}=\mathbf{2 8})\end{array}$ & $\begin{array}{l}\text { Controls } \\
(\mathbf{n}=\mathbf{2 8})\end{array}$ & p-value \\
\hline $\mathrm{BHI}(\%)$ & $1.02 \pm 0.4$ & $1.02 \pm 0.3$ & 0.993 \\
$\mathrm{MFV}_{\text {rest }}$ & $57.6 \pm 14.7$ & $58.6 \pm 19.2$ & 0.849 \\
$\mathrm{MFV}_{\text {apnea }}$ & $74.4 \pm 18.6$ & $69.9 \pm 20.7$ & 0.448 \\
$\mathrm{MFV}$ variations & $16.7 \pm 8.1$ & $11.3 \pm 10.8$ & 0.057 \\
\hline
\end{tabular}

Abbreviations: $\mathrm{BHI}$, breath-holding index; MFV, mean flow velocity; MS, multiple sclerosis; TCD, transcranial Doppler.
Table 4 TCD sonography characteristics of subjects with MS and lacunar infarctions

\begin{tabular}{llll}
\hline & $\begin{array}{l}\text { Lacunar infarction } \\
(\mathbf{n}=\mathbf{2 8})\end{array}$ & $\begin{array}{l}\text { MS } \\
(\mathbf{n}=\mathbf{2 8})\end{array}$ & p-value \\
\hline $\mathrm{BHI}(\%)$ & $0.8 \pm 0.4$ & $1.02 \pm 0.4$ & 0.040 \\
$\mathrm{MFV}_{\text {rest }}$ & $47.2 \pm 14.2$ & $54.8 \pm 2.3$ & 0.010 \\
$\mathrm{MFV}_{\text {apnea }}$ & $58.5 \pm 17.7$ & $74.4 \pm 18.6$ & 0.002 \\
$\mathrm{MFV}$ variations & $11.2 \pm 6.4$ & $16.7 \pm 8.1$ & 0.007 \\
\hline
\end{tabular}

Abbreviations: $\mathrm{BHI}$, breath-holding index; MFV, mean flow velocity; MS, multiple sclerosis; TCD, transcranial Doppler.

patients with lacunar infarction. This finding demonstrates that BHI might be a reliable and accurate index for differentiating ischemic lesions from demyelinating ones.

Cerebral autoregulation is the innate potential of the cerebral blood vessels to maintain and regulate the $\mathrm{CBF}$ in a constant range despite a wide range of systemic BP levels. Cerebral blood vessels undertake autoregulation through a complex of myogenic, neurogenic, and metabolic mechanisms. Several factors are responsible for cerebral autoregulation, the most important of which include vascular conductance and arterial BP. ${ }^{19}$ In addition, it has been shown that arterial $\mathrm{CO}_{2}$ concentrations are the most important factor by which the $\mathrm{CBF}$ is regulated..$^{20}$ When the cerebral perfusion pressure is modified, blood vessels adapt their vascular resistance in order to maintain the CFB at its baseline. ${ }^{21,22}$ The lower and upper limits of cerebral autoregulation in the normotensive human are considered to be at mean arterial pressures of 60 and $150 \mathrm{mmHg}$, between which the $\mathrm{CBF}$ remains relatively constant. Cerebral autoregulation has been found to be damaged in several conditions including head injury, ${ }^{12}$ ischemic stroke, ${ }^{5}$ and subarachnoid hemorrhage. ${ }^{23,24}$ This vicious cycle imposes fluctuations in perfusion pressure in the brain and is associated with worse prognosis.

It has been previously demonstrated that cerebral autoregulation is impaired in ischemic stroke (even in minor stroke), probably secondary to cerebral vasculature endothelial dysfunction as well as venous thrombosis. ${ }^{5,19}$ Maintenance of cerebral perfusion during ischemia and stroke is important to conserve and protect the penumbral tissue. Autoregulation is responsible for maintaining cerebral perfusion during stroke and even during interventions in stroke units including BP manipulation, mobilization, and angiographic interventions. However, cerebral autoregulation is impaired secondary to ischemia, and this results in a vicious cycle leading to increased ischemic area and decreased penumbra. It has been demonstrated that cerebral autoregulation is impaired in both hemispheres when an ischemia in the territory of large intracranial vessels occurs. The most interesting finding is 
that this bilateral effect seems to be more pronounced in lacunar stroke. ${ }^{5}$ It has been demonstrated that the impairment of the cerebral vasoreactivity occurs within the first days after the ischemia, but the recovery lasts for several months. ${ }^{25,26}$ Impaired cerebral autoregulation in stroke is related to acute neurological deterioration, necessity of decompressive surgery, and poor outcome. All of these evidences are in concordance with our study that revealed impaired cerebral autoregulation in lacunar infarction.

We found that cerebral autoregulation remains intact in patients suffering from MS when compared to healthy ageand sex-matched controls, and this is in concordance with a similar previous study. ${ }^{10}$ Previous studies have determined the cardiovascular autonomic response in MS patients in comparison to healthy individuals. However, they have revealed conflicting results, probably because of different patient selection criteria. Some of these studies have shown that $>50 \%$ of patients with MS suffer from cardiovascular autonomic dysfunction, whereas some others have reported no significant differences in these patients, similar to our observations in the present study. ${ }^{27,28}$ Most studies have reported a significant association between increased MS severity and cardiovascular autonomic dysfunction. ${ }^{29}$ In another study, Ozkan et $\mathrm{al}^{30}$ revealed that blood flow velocities were significantly lower than that in controls during attack periods, and increased during the attack-free period along with clinical improvement. Additionally, vasoreactivity was significantly higher during the attack period, and decreased during the attack-free period; however, it was still significantly higher than in the controls. These findings are in agreement with our study. It is suggested that MS patients have a more reactive posterior circulation than healthy subjects. ${ }^{10}$ In this regard, Sloper et $\mathrm{al}^{31}$ showed that recurrent hypoxia leads to degeneration in GABA terminals of inhibitory neurons as well as a failure in the cortical inhibitory system.

There are several factors affecting cerebral vasoreactivity and brain autoregulation. These factors include aging, vascular sclerosis, DM, and HIV cerebritis. ${ }^{32-34}$ Age-related decreases in baseline CBF and CVR are observed in the cerebral cortex, which may be related to the vulnerability for neurological disorders with aging. ${ }^{32}$ In our study as the patients with MS had a significantly lower age compared to those with lacunar infarction, it might have affected the results. However, we found that patients with MS had comparable indices with older healthy controls. Thus, we can conclude that lacunar infarctions are associated with decreased cerebral vasoreactivity, which could be exacerbated with advanced age. The other factor that might affect the vasoreactivity measurement in patients with MS is the volume and number of the lesions. ${ }^{35}$ As we have not undertaken MS lesion volumetry, we cannot comment on the issue.

We had some limitations with regard to this study, of which the most important is that it had a small study population. Future studies with larger study populations are needed to shed light on this issue. The other limitation was that patients with lacunar infarction had a significantly higher age when compared to those with MS. In addition, they had a significantly higher male-to-female ratio when compared to the MS group. It is well established that BHI is affected by both age and sex, being lower in women and decreasing by the age especially in women. ${ }^{18}$ Although this could be responsible for the lower BHI in MS patients compared to those in the lacunar infarction group, the evidence suggests that impaired cerebral autoregulation is the main reason for this findings.

In conclusion, demyelinating lesions are associated with higher vasoreactivity compared to ischemic ones. In other words, cerebral autoregulation is impaired in ischemic stroke whereas it seems to remain intact in MS. Thus, cerebral vasoreactivity measured by TCD sonography can be used for differentiating ischemic and demyelinating lesions.

\section{Acknowledgments}

The authors acknowledge the participation of the patients and their families in the current study. The current article is the result of a thesis by Dr Anahita Zoghi for partial fulfillment of the requirement for a specialty degree in clinical neurology (grant no 2662). The abstract of this paper was presented at the 16th Congress of the European Federation of Neurological Societies as a poster presentation with interim findings. The poster's abstract was published in "Poster Abstracts" in the European Journal of Neurology: https://onlinelibrary.wiley. com/doi/epdf/10.1111/j.1468-1331.2012.03889.x.

\section{Disclosure}

The authors report no conflicts of interest in this work.

\section{References}

1. Kulshreshtha A, Anderson LM, Goyal A, Keenan NL. Stroke in South Asia: a systematic review of epidemiologic literature from 1980 to 2010. Neuroepidemiology. 2012;38(3):123-129.

2. Wieberdink RG, Ikram MA, Hofman A, Koudstaal PJ, Breteler MM. Trends in stroke incidence rates and stroke risk factors in Rotterdam, the Netherlands from 1990 to 2008. Eur J Epidemiol. 2012;27(4) 287-295.

3. Venketasubramanian N, Yoon BW, Pandian J, Navarro JC. Stroke epidemiology in south, east, and south-east Asia: a review. J Stroke. 2017; 19(3):286-294. 
4. Xiong L, Liu X, Shang T, et al. Impaired cerebral autoregulation: measurement and application to stroke. J Neurol Neurosurg Psychiatry. 2017;88(6):520-531.

5. Aries MJ, Elting JW, De Keyser J, Kremer BP, Vroomen PC. Cerebral autoregulation in stroke: a review of transcranial Doppler studies. Stroke. 2010;41(11):2697-2704.

6. Zhou D, Meng R, Li SJ, et al. Advances in chronic cerebral circulation insufficiency. CNS Neurosci Ther. 2018;24(1):5-17.

7. Elhami SR, Mohammad K, Sahraian MA, Eftekhar H. A 20-year incidence trend (1989-2008) and point prevalence (March 20, 2009) of multiple sclerosis in Tehran, Iran: a population-based study. Neuroepidemiology. 2011;36(3):141-147.

8. Kornek B, Lassmann H. Neuropathology of multiple sclerosis-new concepts. Brain Res Bull. 2003;61(3):321-326.

9. Marshall O, Chawla S, Lu H, Pape L, Ge Y. Cerebral blood flow modulation insufficiency in brain networks in multiple sclerosis: a hypercapnia MRI study. J Cereb Blood Flow Metab. 2016;36(12):2087-2095.

10. Marshall O, Lu H, Brisset JC, et al. Impaired cerebrovascular reactivity in multiple sclerosis. JAMA Neurol. 2014;71(10):1275-1281.

11. Ingram $\mathrm{G}$, Loveless $\mathrm{S}$, Howell $\mathrm{OW}$, et al. Complement activation in multiple sclerosis plaques: an immunohistochemical analysis. Acta Neuropathol Commun. 2014;2:53.

12. Bruce CD, Steinback CD, Chauhan UV, et al. Quantifying cerebrovascular reactivity in anterior and posterior cerebral circulations during voluntary breath holding. Exp Physiol. 2016;101(12):1517-1527.

13. Ge Y, Law M, Johnson G, et al. Dynamic susceptibility contrast perfusion $\mathrm{mr}$ imaging of multiple sclerosis lesions: characterizing hemodynamic impairment and inflammatory activity. AJNR Am J Neuroradiol. 2005;26(6):1539-1547.

14. Monti L, Morbidelli L, Bazzani L, Rossi A. Influence of circulating endothelin-1 and asymmetric dimethylarginine on whole brain circulation time in multiple sclerosis. Biomark Insights. 2017;12: 1177271917712514

15. Polman CH, Reingold SC, Banwell B, et al. Diagnostic criteria for multiple sclerosis: 2010 revisions to the McDonald criteria. Ann Neurol. 2011;69(2):292-302.

16. Liu W, Liu J, Lou X, et al. A longitudinal study of cerebral blood flow under hypoxia at high altitude using 3D pseudo-continuous arterial spin labeling. Sci Rep. 2017;7:43246.

17. Okonkwo DO, Shutter LA, Moore C, et al. Brain oxygen optimization in severe traumatic brain injury phase-II: a phase II randomized trial. Crit Care Med. 2017;45(11):1907-1914.

18. Mousavi SA, Khorvash F, Asadi B, Karkheiran F. Evaluation of vasomotor reactivity by transcranial Doppler sonography: age and sex related differences in breath holding index in Iranian population. J Res Med Sci. 2005;10(2):93-96.

19. Johnston AJ, Steiner LA, Gupta AK, Menon DK. Cerebral oxygen vasoreactivity and cerebral tissue oxygen reactivity. Br J Anaesth. 2003; 90(6):774-786.
20. Wang D, Parthasarathy AB, Baker WB, et al. Fast blood flow monitoring in deep tissues with real-time software correlators. Biomed Opt Express. 2016;7(3):776-797.

21. Panerai RB. Transcranial Doppler for evaluation of cerebral autoregulation. Clin Auton Res. 2009;19(4):197-211.

22. van Beek AH, Claassen JA, Rikkert MG, Jansen RW. Cerebral autoregulation: an overview of current concepts and methodology with special focus on the elderly. J Cereb Blood Flow Metab. 2008;28(6): 1071-1085.

23. Müller MW, Österreich M, Müller A, Lygeros J. Assessment of the brain's macro- and micro-circulatory blood flow responses to $\mathrm{CO}_{2}$ via transfer function analysis. Front Physiol. 2016;7:162.

24. Salinet AS, Robinson TG, Panerai RB. Effects of cerebral ischemia on human neurovascular coupling, $\mathrm{CO}_{2}$ reactivity, and dynamic cerebral autoregulation. J Appl Physiol (1985). 2015;118(2):170-177.

25. Reinhard M, Roth M, Guschlbauer B, et al. Dynamic cerebral autoregulation in acute ischemic stroke assessed from spontaneous blood pressure fluctuations. Stroke. 2005;36(8):1684-1689.

26. Reinhard M, Wihler C, Roth M, et al. Cerebral autoregulation dynamics in acute ischemic stroke after rtPA thrombolysis. Cerebrovasc Dis. 2008;26(2):147-155.

27. Videira G, Castro P, Vieira B, et al. Autonomic dysfunction in multiple sclerosis is better detected by heart rate variability and is not correlated with central autonomic network damage. J Neurol Sci. 2016;367: 133-137.

28. Vieira B, Costa A, Videira G, Sá MJ, Abreu P. Prevalence of autonomic dysfunction in patients with multiple sclerosis. Acta Med Port. 2015; 28(1):51-55.

29. Sander C, Hildebrandt H, Schlake HP, Eling P, Hanken K. Subjective cognitive fatigue and autonomic abnormalities in multiple sclerosis patients. Front Neurol. 2017;8:475.

30. Ozkan S, Uzuner N, Kutlu C, Ozbabalik D, Ozdemir G. The effect of methylprednisolone treatment on cerebral reactivity in patients with multiple sclerosis. J Clin Neurosci. 2006;13(2):214-217.

31. Sloper JJ, Johnson P, Powell TP. Selective degeneration of interneurons in the motor cortex of infant monkeys following controlled hypoxia: a possible cause of epilepsy. Brain Res. 1980;198(1):204-209.

32. Leoni RF, Oliveira IA, Pontes-Neto OM, Santos AC, Leite JP. Cerebral blood flow and vasoreactivity in aging: an arterial spin labeling study. Braz J Med Biol Res. 2017;50(4):e5670.

33. Chung CC, Pimentel D, Jor'dan AJ, Hao Y, Milberg W, Novak V. Inflammation-associated declines in cerebral vasoreactivity and cognition in type 2 diabetes. Neurology. 2015;85(5):450-458.

34. Chow FC, Boscardin WJ, Mills C, et al. Cerebral vasoreactivity is impaired in treated, virally suppressed HIV-infected individuals. AIDS. 2016;30(1):45-55.

35. Geraldes R, Esiri MM, DeLuca GC, Palace J. Age-related small vessel disease: a potential contributor to neurodegeneration in multiple sclerosis. Brain Pathol. 2017;27(6):707-722.
Neuropsychiatric Disease and Treatment

\section{Publish your work in this journal}

Neuropsychiatric Disease and Treatment is an international, peerreviewed journal of clinical therapeutics and pharmacology focusing on concise rapid reporting of clinical or pre-clinical studies on a range of neuropsychiatric and neurological disorders. This journal is indexed on PubMed Central, the 'PsycINFO' database and CAS,

\section{Dovepress}

and is the official journal of The International Neuropsychiatric Association (INA). The manuscript management system is completely online and includes a very quick and fair peer-review system, which is all easy to use. Visit http://www.dovepress.com/testimonials.php to read real quotes from published authors. 